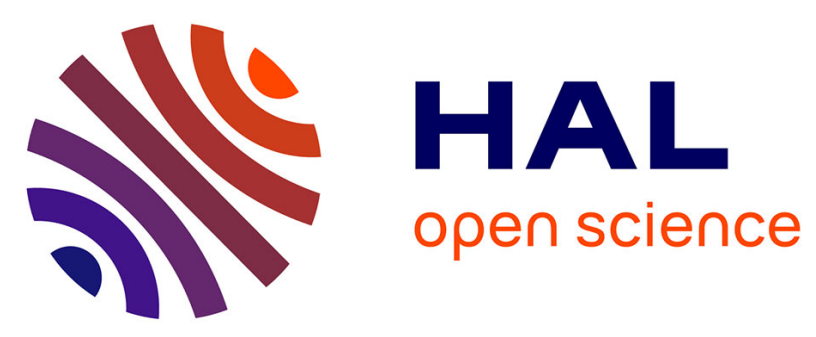

\title{
Zirconia abutments in the anterior region: A systematic review of mechanical and esthetic outcomes
}

\author{
Adrien Naveau, Christophe Rignon-Bret, Claudine Wulfman
}

\section{To cite this version:}

Adrien Naveau, Christophe Rignon-Bret, Claudine Wulfman. Zirconia abutments in the anterior region: A systematic review of mechanical and esthetic outcomes. Journal of Prosthetic Dentistry, 2019, 121, pp.775 - 781.e1. 10.1016/j.prosdent.2018.08.005 . hal-03485083

\section{HAL Id: hal-03485083 \\ https://hal.science/hal-03485083}

Submitted on 21 Dec 2021

HAL is a multi-disciplinary open access archive for the deposit and dissemination of scientific research documents, whether they are published or not. The documents may come from teaching and research institutions in France or abroad, or from public or private research centers.
L'archive ouverte pluridisciplinaire $\mathbf{H A L}$, est destinée au dépôt et à la diffusion de documents scientifiques de niveau recherche, publiés ou non, émanant des établissements d'enseignement et de recherche français ou étrangers, des laboratoires publics ou privés.

\section{다)(1) $(5$}

Distributed under a Creative Commons Attribution - NonCommerciall 4.0 International 


\section{Post-emplacement dynamics of andesitic lava flows at}

\section{Volcán de Colima, Mexico, revealed by radar and optical}

\section{3 remote sensing data}

4

5

6 7 France

8

9

10

11

12 13 flows.

14

15

16

17

Alexandre Carrara ${ }^{1 *}$, Virginie Pinel ${ }^{1}$, Pascale Bascou $^{1}$, Emmanuel Chaljub $^{1}$, Servando De la Cruz-Reyna ${ }^{2}$

${ }^{1}$ Univ. Grenoble Alpes, Univ. Savoie Mont Blanc, CNRS, IRD, IFSTTAR, ISTerre, 38000 Grenoble,

${ }^{2}$ Instituto de Geofisica, Universidad Nacional Autónoma de Mexico, CDMX 04510, Mexico

* Corresponding author: Alexandre Carrara (carrara.alexandre.univ@gmail.com)

Highlights:-We propose a novel approach for retrieving a 3D displacement field on lava

-We measure horizontal motion on a lava flow several months after its emplacement.

-Thermal contraction, loading and flow all contribute to the displacements.

Abstract : 281 words ; Main text : 9510 words, 4 tables, 11 figures, 65 references

p. 1 


\section{Abstract:}

We used optical and radar remote sensing datasets to map, estimate the volume, and measure the surface displacements of lava flows emplaced on the flanks of Volcán de Colima, Mexico by extrusion of lava dome material from the end of 2014 to early 2016 . Our main result is that the flow motion of the lava contributes significantly to the recorded displacements several months after its emplacement. First, we mapped the deposits and estimated their volumes using two Digital Elevation Models (DEM), one derived from radar data acquired before the peak of activity and one derived from optical images acquired just after this peak of activity. Coherence information derived from the radar dataset added some temporal constraints on the timing of emplacement of various deposits. We thus estimated a mean extrusion rate of $1-2 \mathrm{~m}^{3} \mathrm{~s}^{-1}$ between November 2014 and February 2015. We then used a new approach to reconstruct the 3D displacement field, taking advantage of images acquired by the same satellite, on both ascending and descending tracks, and using a physical a priori on the direction of horizontal displacements. Our results show that about $2 \mathrm{~cm} \mathrm{yr}^{-1}$ of horizontal motion is still recorded a few months after the emplacement on the SW lava flow, which is the only one covered by the two-acquisition geometries. In order to differentiate the potential causes of the observed displacements, we modeled the thermal contraction of the lava flow using a finite element numerical method. Removing the contribution of thermoelastic contraction from the measured displacements enable to infer both the viscoelastic loading and flow motion effects from the residuals. Results show that, thermal contraction, flow motion and viscoelastic loading contribute significantly to the displacements recorded.

\section{Keywords:}


- Remote sensing, InSAR, 3D displacement field, lava flow, subsidence, thermal contraction.

(1)

\section{Introduction:}

Spaceborne remote sensing datasets, providing information with a good spatial coverage over areas that are difficult to access, have proven to be powerful tools to study lava flows. Radar images have the advantage that they are insensitive to cloud cover and solar lighting. They can be used to detect and map new lava flows with either coherence or amplitude based methods (Schaber et al., 1980; Zebker et al., 1987, 1996; Gaddis, 1992; Rowland et al., 2003; Dietterich et al., 2012). They are also commonly used to estimate their thickness and volume, and thus determine volcano extrusion rates (Stevens et al., 1999; Rowland et al., 2003; Terunuma, et al., 2005; Poland, 2014; Bato et al., 2016; Arnold et al., 2017), which is key information in terms of hazard assessment. Interferometry has been used to study the post-emplacement dynamics of lava flows (e.g. Briole et al., 1997; Lu et al., 2005; Ebmeier et al., 2012; Bato et al., 2016; Chaussard, 2016, see table 1), and in turn, calculate their material properties (Wittmann et al., 2017). However, most of these studies were performed on basaltic lava flows emplaced on gentle topographic slopes (see table 1), where lava flows are frequent and InSAR is highly effective. On the contrary, it is well-established that InSAR methods are more difficult to use on andesitic stratovolcanoes because of their steep topography and generally dense vegetation coverage, causing low coherence and noisy data (Pinel et al., 2011). A limitation to the use of InSAR to characterize postemplacement deformation of lava flows is that, in the absence of additional measurements of the surface displacement such as GNSS or SAR acquired from a different satellite (Peltier et al., 2017), 
62 radar images acquired by a given satellite for both the ascending and descending tracks are

63 difficult to use to reconstruct the 3D displacement fields due to the lower accuracy in the north64 south $(\mathrm{N}-\mathrm{S})$ direction (InSAR measurements being only sensitive to the displacements along the

65 satellite line of sight, which horizontal projection is usually close to the east-west direction for both ascending and descending tracks). Thus, most studies consider that the Line of Sight (LOS) displacements measured result from vertical displacements alone. This assumption prevents the extraction of information about the lava flows horizontal displacement fields being extracted, and could introduce an error into the estimated vertical displacements.

Volcán de Colima, one of the most active volcanoes in North America, is located at the SW front of the Trans Mexican Volcanic Belt (Fig. 1), created by the subduction of the Cocos and Rivera plates under the North American plate. Volcanic activity is characterized by cycles of around one hundred years which culminate in a large Plinian eruption; the last major explosive eruption was in 1913 (Robin et al., 1987; Luhr and Carmichael, 1990).

A new episode of mostly effusive activity began in 1961, when the lava that had slowly infilled the crater left by the 1913 explosions reached the lowest notch in the northern crater rim, generating block-lava flows. Similar episodes of activity followed in 1975-1976 and 1981-1982. In 1991 the lava extrusion began to form a lava dome that fed new block-lava flows (Luhr, 2002). Collapses of the crater rim and the overflowing dome have since caused numerous block and ash flows, particularly in 2004-2005. Dome-building activity resumed in 2007. Vulcanian explosions destroyed the dome in early 2013, and a new dome began growing again overflowing from the crater and producing further lava flows in March 2013 (Capra et al, 2016). 
At the end of 2014, an increase in eruptive activity was recorded, notably marked by the

July 10 and 11, 2015 pyroclastic density currents (PDCs) which represented the largest runout since 1913 (Capra et al., 2016; Reyes-Dávila et al., 2016; Macorps et al., 2017). The 2015 eruption was not preceded by any detectable precursors in terms of edifice inflation or seismic velocity variations (Lesage et al., 2018). Before and after these events, large lava flows were emplaced on the volcano flanks (Reyes-Dávila et al., 2016). Activity reports describe active lava flows on the western (W) and south-western (SW) flanks from September-November 2014 to mid-February 2015, when no downward motion was observed (Sennert, 2015a). In July, 2015, just after the PDC occurrences, another lava flow formed on the southern (S) flank in the same channel as the PDCS (Sennert, 2015b). Most of studies about this high activity period deal with PDC deposits (Capra et al., 2016; Reyes-Dávila et al., 2016; Macorps et al., 2017) but lava flows should also be considered in order to properly characterize and understand the volcano activity.

The present study combines both radar and optical remote sensing data with the aim of determining where lava flows were emplaced as well as their volumes and their postemplacement dynamics, in order to have greater insight into the 2014-2015 eruptive crisis of Volcán de Colima. New approaches are proposed to: (1) improve the remote sensing detection of lava flows on andesitic stratovolcanoes, and (2) reconstruct approximate 3D ground displacements associated with the emplacement of lava flows using InSAR LOS measurements on both the ascending and descending tracks from a single satellite, without any other additional observation. Finally, the thermal compaction of the lava flow is numerically modeled and its relative contribution together with the loading and downward flow effect, are investigated. An estimation of the magma bulk viscosity is also derived based on the downward lava displacement. 


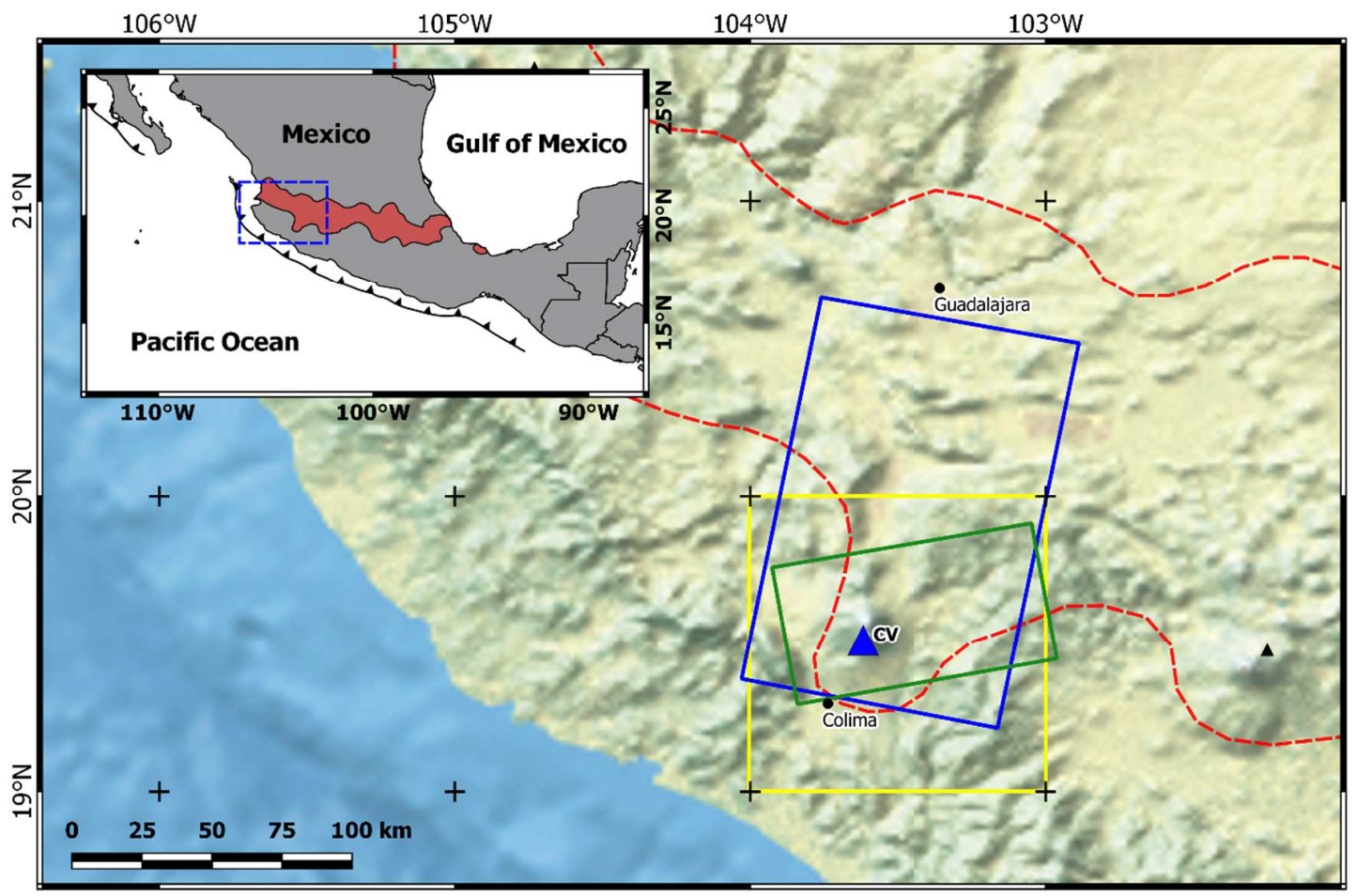

106 Figure 1: Map with footprints of optical and radar images used in this study. The red dashed line 107 marks the edge of the Trans Mexican Volcanic Belt (TMVB) (red area in the inset). The large blue 108 triangle shows the location of Volcán de Colima (CV). Green and blue rectangles are, respectively, 109 footprints of Sentinel-1A ascending (Orbit A49, sub-swath 3) and descending tracks (Orbit D12, 110 sub-swath 1) (for simplicity, only the bursts and sub-swaths used are delimited). The yellow 111 rectangle delimits the extent of Tandem-X DEM. Inset shows the described area location (dashed 112 blue rectangle) at a larger scale. The PLEIADES DEM coverage (10×13 $\mathrm{km}^{2}$ centered on the edifice 113 summit) is not displayed here for clarity. 


\begin{tabular}{|c|c|c|c|c|}
\hline Volcano (deposit year) & Time span (yrs) & Lava composition & Local slope & Ref \\
\hline \multicolumn{5}{|l|}{ Africa } \\
\hline Fogo (1995) & 3 & Basaltic & $\sim 3^{\circ}$ & (Amelung and Day, 2002) \\
\hline Piton de la Fournaise (1998-2007) & $2-16$ & Basaltic & $\sim 17^{\circ}$ & (Chen et al., 2018) \\
\hline (2010) & $0.3-3$ & Basaltic & $\sim 7^{\circ}$ & (Bato et al., 2016) \\
\hline Mt Nyamuragira (2004-2010) & $0-5.5$ & Basaltic & $\sim 4^{\circ}$ & $\begin{array}{l}\text { (Samsonov and d'Oreye, } \\
\text { 2012) }\end{array}$ \\
\hline \multicolumn{5}{|l|}{ North America } \\
\hline Paricutin (1943-1952) & $55-68$ & Basaltic-Andesitic & $\sim 5^{\circ}$ & (Chaussard, 2016) \\
\hline$(1943-1952)$ & $56-65$ & Basaltic-Andesitic & $\sim 8^{\circ}$ & (Fournier et al., 2010) \\
\hline Santiaguito (2004-2005) & $4-6$ & Dacitic & $\sim 21^{\circ}$ & (Ebmeier et al., 2012) \\
\hline Okmok (1958 \& 1997) & $0.5-3.5$ & Basaltic & $\sim 1^{\circ}$ & (Lu et al., 2005) \\
\hline Colima (1998) & $4-8$ & Andesitic & $\sim 25^{\circ}$ & (Pinel et al., 2011) \\
\hline (2014-2015) & $0.5-1.1$ & Andesitic & $\sim 18^{\circ}$ & This study \\
\hline Pacaya (2010) & $0.1-4$ & Basaltic & $\sim 10^{\circ}$ & (Schaefer et al., 2016) \\
\hline \multicolumn{5}{|l|}{ Europe } \\
\hline Etna (1986-1987 \& 1989) & $3-7$ & Basaltic & $\sim 23^{\circ}$ & (Briole et al., 1997) \\
\hline (1991-1993) & $2-6$ & Basaltic & $\sim 13^{\circ}$ & (Stevens et al., 2001) \\
\hline Krafla (1975-1984) & $8-20$ & Basaltic & $\sim 1^{\circ}$ & (Sigmundsson et al., 1997) \\
\hline Hekla (1991 \& 2000) & $2-25$ & Basaltic-Andesitic & $\sim 8^{\circ}$ & (Wittmann et al., 2017) \\
\hline \multicolumn{5}{|l|}{ South America } \\
\hline Reventador (2002-2005) & $3-6$ & Andesitic & $\sim 18^{\circ}$ & (Fournier et al., 2010) \\
\hline Lonquinay (1988-1989) & $17-18$ & Andesitic & $\sim 4^{\circ}$ & (Fournier et al., 2010) \\
\hline
\end{tabular}

116 Table 1: List of the InSAR studies related to lava flow post-emplacement deformations. Local

117 slope was estimated from the SRTM DEM. Time span corresponds to the time lapse between

118 the lava flow emplacement and SAR image acquisition. 
Digital Elevation Models (DEM). The pre-eruptive DEM used is the TanDEM-X, $12 \mathrm{~m}$ resolution, provided by the German Space Agency (CDLR 2015) and obtained from X-band radar images acquired between January 2011 and August 2014 (see footprint on Fig. 1). A post-eruptive DEM was obtained using one stereo pair of Pleiades optical images (CCNES_2016, distribution AIRBUS DS, France, all rights reserved) acquired on 10 January 2016 and made available through an ISIS (Incitation à l'utilisation Scientifique des Images Spot, French initiative to promote the scientific use of Spot images) project. Pleiades panchromatic images have a nominal resolution of $0.5 \mathrm{~m}$. Along-track incidence angles of the two images are $-9.3^{\circ}$ and $-13.1^{\circ}$, while the across-track angle varies between $-14.5^{\circ}$ and $-9.6^{\circ}$. The DEM was computed using the NASA open source software Ames Stereo Pipeline (Broxton and Edwards, 2008). Disparities between the two images are searched for; this provides a point cloud of the surface topography which is then converted onto a grid regularly spaced every $3 \mathrm{~m}$. In this way we obtain a Digital Surface Model, but as no vegetation is present on the region of interest, where lava flows are emplaced, it corresponds to a DEM.

Surface displacements induced by the lava flows were quantified based on 36 SAR images acquired from November 23, 2014 to February 10, 2016, on both ascending and descending tracks, by the European satellite Sentinel-1A with a Vertical-Vertical polarization (Table 2). Images were acquired in Terrain Observation by Progressive Scans SAR (TOPSAR) Interferometric Wide Swath mode (Zan and Guarnieri, 2006) and provided as Single Look Complex (SLC) images with a spatial resolution of $15.6 \mathrm{~m}$ in azimuth and $2.3 \mathrm{~m}$ in slant range (see Fig. 2 for spatio-temporal distribution of the dataset). As Volcán de Colima's flanks are steep, local topographic slopes are 
close to or even greater than the incidence angle, inducing low resolution and a possible layover effect on the flanks facing the satellite. This is particularly true for the descending track where the incidence angle is very close to the volcano slope on the eastern flanks around the summit area $\left(\sim 35^{\circ}\right)$. Ground area affected by low resolution was estimated and consequently masked based on acquisition geometries.

Interferograms as well as coherence images were computed on ascending and descending tracks from SLC images using the NSBAS processing chain as described in Doin et al (2012) and modified to allow for TOPSAR data ingestion (Grandin, 2015). Topographic phase contribution was removed using the SRTM Digital Elevation Model at $30 \mathrm{~m}$ resolution oversampled to $15 \mathrm{~m}$. Interferograms were corrected for tropospheric phase delays using atmospheric data provided by the European Center for Medium Range Weather Forecast (ECMRWF) (Doin et al., 2009). Interferograms were then unwrapped using the ROI_PAC branch-cut unwrapping algorithm. Phase delays were converted to LOS ground displacements considering ground displacement as null in a $255 \times 255$ m reference area located at the basal part of the SW volcano sector (see Fig. 67). Cumulative LOS ground displacements for each successive date after to the first one were obtained by time series inversion, pixel by pixel, using a least squares method (Doin et al., 2012). Lastly, cumulative displacements were geocoded in UTM coordinates on the oversampled SRTM DEM used to correct the topographic phase delay $(15 \times 15 \mathrm{~m})$. The time series analysis was performed on a restricted subset of the data to ensure good coherence over the lava flows. As the coherence was too low on lava flows for images acquired before the July eruption (Lesage et al., 2018), we only considered interferograms obtained from images acquired after August 2015 (see Fig. 2B-C). 


\begin{tabular}{|c|c|c|c|}
\hline Date & Orbite-Slice Sub-swath & Date & Orbite-Slice Sub-swath \\
\hline 23 Nov 2014 & D12-4 IW1 & 24 Jul 2015 & A49-1 IW3 \\
\hline 08 Dec 2014 & A49-1 IW3 & 02 Aug 2015 & D12-4 IW1 \\
\hline 17 Dec 2014 & D12-4 IW1 & 17 Aug 2015 & A49-1 IW3 \\
\hline 01 Jan 2015 & A49-1 IW3 & 26 Aug 2015 & D12-4 IW1 \\
\hline 10 Jan 2015 & D12-4 IW1 & 19 Sep 2015 & D12-4 IW1 \\
\hline 03 Feb 2015 & D12-4 IW1 & 13 Oct 2015 & D12-4 IW1 \\
\hline 18 Feb 2015 & A49-1 IW3 & 28 Oct 2015 & A49-1 IW3 \\
\hline 02 Mar 2015 & A49-1 IW3 & 06 Nov 2015 & D12-4 IW1 \\
\hline 11 Mar 2015 & D12-4 IW1 & 30 Nov 2015 & D12-4 IW1 \\
\hline 23 Mar 2015 & A49-1 IW3 & 15 Dec 2015 & A49-2 IW3 \\
\hline 04 Apr 2015 & D12-4 IW1 & 24 Dec 2015 & D12-4 IW1 \\
\hline 28 Apr 2015 & D12-4 IW1 & 27 Dec 2015 & A49-2 IW3 \\
\hline 22 May 2015 & D12-4 IW1 & 08 Jan 2016 & A49-2 IW3 \\
\hline 06 Jun 2015 & A49-1 IW3 & 17 Jan 2016 & D12-4 IW1 \\
\hline 15 Jun 2015 & D12-4 IW1 & 01 Feb 2016 & A49-2 IW3 \\
\hline 30 Jun 2015 & A49-1 IW3 & 10 Feb 2016 & D12-4 IW1 \\
\hline $07 \mathrm{Jul} 2015$ & D12-4 IW1 & 25 Feb 2016 & A49-2 IW3 \\
\hline
\end{tabular}

165 Table 2: List of the Sentinel-1A SAR images used in this study. Information on the acquisition

166 geometry for each track is provided in Table 3.

167
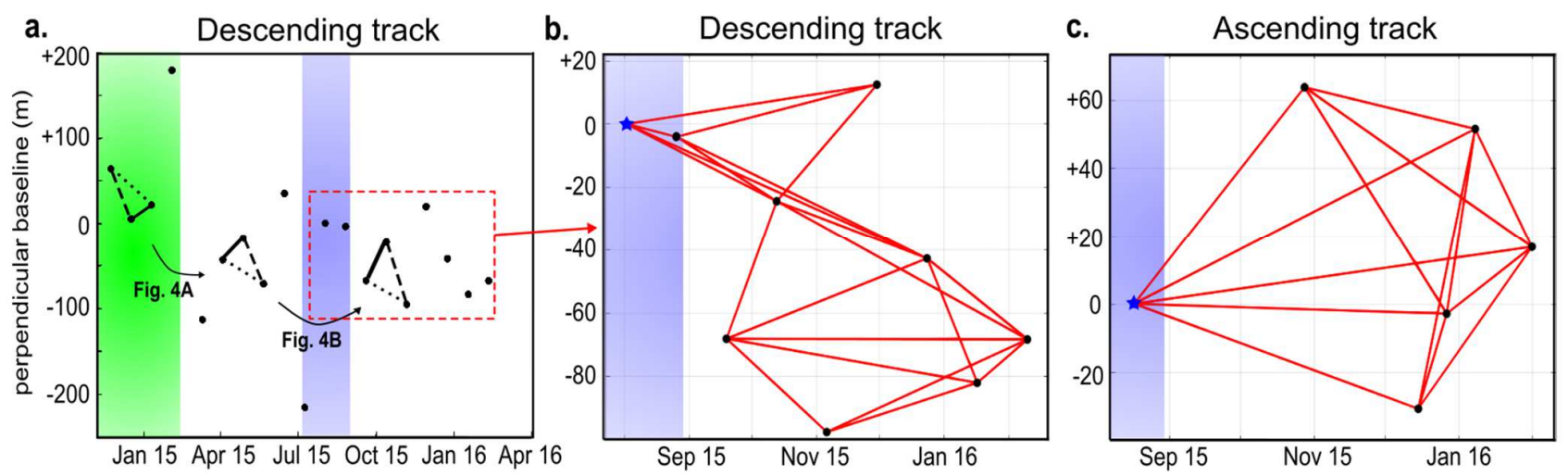

p. 10 